\title{
A incidência da CPM F nas operações simbólicas de câmbio
}

\author{
Mariane Santos Fernandes ${ }^{1}$ \\ Marisa Trentini da Silva ${ }^{2}$
}

\begin{abstract}
Resumo
O esboço da Regra Matriz de Incidência Fiscal de um tributo é fundamental para a determinação da hipótese tributária e sua conseqüente relação jurídica tributária. Nas Operações Simbólicas de Câmbio (transação de entrada e saída de dinheiro do país), em que há incidência da Contribuição Provisória sobre Movimentação Financeira - CPMF, não é diferente. Sobre a questão, surgem inúmeros questionamentos, tais como a sua natureza fictícia e a não previsão legal na Lei 9.311/1996 e Instrução Normativa 450/2004. Frente a isso, a incidência da CPM F, nas referidas operações, revela flagrante ilegalidade, ante a violação a princípios constitucionais tributários.
\end{abstract}

Palavras-Chave: CPM F. Regra Matriz. Operações Simbólicas. Ilegalidade. Inconstitucionalidade.

\section{Introdução}

0 presente artigo tem por objetivo analisar a incidência (ou não) da CPM F nas operações de Câmbio Simbólico, em que há saída e entrada de dinheiro no país.

Para tanto, é imprescindível que se faça uma breve análise da Regra Matriz de Incidência Fiscal, relativa à Contribuição Provisória sobre M ovimentação Financeira - CPM F, haja vista que, para que seja possível a formação da relação jurídica tributária, irrompendo o vínculo obrigacional, formando-se o crédito tributário e conseqüente dever de pagar o tributo, faz-se necessária a verificação da subsunção do fato (evento tributário) à norma abstrata (hipótese tributária), legalmente prevista no ordenamento jurídico pátrio.

Dessa forma, a Hipótese Tributária da CPM F, através do critério material, espacial e temporal, que a compõe, irá fornecer subsídios importantes para análise que se busca fazer, a fim de compreender se há ou não incidência do referido tributo nas operações simbólicas de câmbio.

\footnotetext{
${ }^{1}$ Acadêmica do 50 ano matutino do curso de Direito da Universidade Estadual de Londrina

${ }^{2}$ Acadêmica do 50 ano matutino do curso de Direito da Universidade Estadual de Londrina
} 


\section{Regra matriz de incidência fiscal da CPMF}

A Regra M atriz de Incidência fiscal é composta por uma Hipótese Tributária, a qual descreve, de modo abstrato, um evento tributário. É possível verificar a ocorrência de tal evento, no instante em que há a projeção factual de um fato, isto é, na ocorrência de um fato, relevante para legislador tributário, no plano real, nas relações sociais, resultando um fato jurídico tributário, cuja função é descrever de modo concreto o evento.

Para Carvalho (2004, p. 244), a Hipótese Tributária é a descrição normativa de um evento que, concretizado no nível das realidades materiais e relatado no antecedente de norma individual e concreta, fará irromper o vinculo abstrato que o legislador estipulou na conseqüência. Há a subsunção do fato à norma, quando o fato (fato jurídico tributário constituído pela linguagem pescrita pelo direito positivo) guardar absoluta identidade com 0 desenho normativo da hipótese (hipótese tributária).

A Hipótese Tributária ou Hipótese de Incidência, nas palavras de Ataliba (2004, p. 58), é a descrição legal de um fato: é a formulação hipotética, prévia e genérica, contida na lei, de um fato.

A Hipótese Tributária possui três critérios de identificação: material, espacial e territorial.

\section{Critério material}

Conforme preceitua Carvalho (2004, p. 253), no critério material há referência a um comportamento de pessoas, físicas ou jurídicas, condicionadas por circunstâncias de espaço e de tempo (critérios espacial e temporal).

A descrição objetiva do fato é o que se obtém da compostura integral da hipótese tributária, enquanto que o critério material é um dos seus componentes lógicos.

Verbo pessoal e de predicação incompleta, o que importa a obrigatória presença de um complemento, para o critério material.

Dessa forma, por critério material entende-se o comportamento de uma pessoa, representado por um verbo e seu complemento, que há de ser delimitado por condições espaciais e temporais, como descrição normativa de um fato. 
Através do critério material, ações são selecionadas para serem submetidas à incidência normativa.

Ataliba (2004, p.106) afirma que o critério material é a descrição dos dados substanciais que servem de suporte à hipótese tributária.

O critério material inserido na hipótese tributária (descrição abstrata de um evento) da CPMF está contido no parágrafo único, do art 1o da Lei 9.311/1996, a qual Institui a Contribuição Provisória sobre Movimentação ou Transmissão de Valores e de Créditos e Direitos de Natureza Financeira - CPMF e demais providências, assim como a Instrução normativa no 450/2004, que disciplina a cobrança e o recolhimento da CPM F, em seu artigo $2^{\circ}$, conforme abaixo:

Art. $2 \underline{\underline{o}}$ Considera-se movimentação ou transmissão de valores e de créditos e direitos de natureza financeira qualquer operação liquidada ou lançamento realizado pelas entidades referidas no art. $3 \underline{\underline{n}}$, que representem circulação escritural ou física de moeda, e de que resulte ou não transferência da titularidade dos mesmos valores, créditos e direitos.

Em síntese, o critério material, contido na hipótese tributária da CPM F consiste na movimentação ou transmissão de valores e de créditos e direitos de natureza financeira.

A Instrução Normativa o 450/2004, em seu artigo art. 20 (parágrafo único, do art. 1ำ, da Lei 9.311/1996), considera como sendo movimentação ou transmissão desses valores, créditos e direitos de natureza financeira, qualquer operação liquidada ou lançamento realizado por instituições financeiras, que representem circulação escritural ou física de moeda e de que resulte ou não transferência de titularidade dos mesmos valores, créditos e direitos, pertencentes à pessoas físicas ou jurídicas.

\section{Critério espacial}

Entende-se por critério espacial o local em que o fato deve ocorrer, a fim de que irradie os efeitos que the são característicos.

Carvalho (2004, p. 258) explica que os elementos indicadores da condição de espaço, contidos na hipótese tributária, terão uma das três formas compositivas do critério espacial: 
a) hipótese cujo critério espacial faz menção a determinado local para a ocorrência do fato típico (Imposto de Importação e Exportação);

b) hipótese em que o critério espacial alude a áreas específicas, o acontecimento apenas ocorrerá se dentro delas estiver geograficamente contido (ITR e IPTU);

c) hipótese de critério espacial bem genérico, onde todo e qualquer fato, que suceda sob o manto da vigência territorial da lei instituidora, estará apto a desencadear seus efeitos peculiares.

É nesta última hipótese que se encaixa o critério espacial, contido na hipótese tributária da CPMF. A Lei 9.311/1996, assim como a Instrução Normativa no 450/2004 não dispuseram sobre o lugar em que o evento jurídico tributário deva ocorrer.

Diante disso, o critério espacial da CPMF coincide com o âmbito de validade territorial da lei, qual seja: qualquer parte do TERRITÓRIO NACIONAL, local onde se considerará ocorrida a movimentação ou transmissão de valores e de créditos e direitos de natureza financeira, haja vista que compete exclusivamente à União legislar sobre contribuições sociais, conforme art. 149 da Constituição Federal, sendo à ela devido esse tributo.

Lembrando que o critério espacial das normas não se confunde com o campo de validade da lei.

\section{Critério temporal}

0 critério temporal, inserido na hipótese tributária, designa o momento em que 0 evento tributário considera-se ocorrido. Salienta-se que o critério temporal não se confunde com a data que o sujeito passivo deve observar para o cumprimento da obrigação tributária.

Carvalho (2004, p. 260-261) explica que o critério temporal da hipótese tributária se refere ao grupo de indicações, contidas no suposto da regra, e que nos oferecem elementos para saber, com exatidão, em que preciso instante acontece o fato descrito, abrindo-se aos sujeitos da relação o exato conhecimento da existência de seus direitos e de suas obrigações.

Segundo Ataliba (2004, p. 94), defini-se aspecto temporal da hipótese de incidência (hipótese tributária) como a propriedade que esta tem de designar (explícita ou implicitamente) o momento em que se deve reputar consumado (acontecido, realizado) um 
fato imponível (evento tributário). Acontecendo concretamente fatos descritos na hipótese de incidência (descrição abstrata contida na lei), depois da vigência da lei em que inserida e enquanto perdure esta - tais fatos serão fatos imponíveis, aptos, portanto, a darem nascimento a obrigações tributárias.

$O$ critério temporal estabelecido para a CPM F é o momento em que é realizada a movimentação ou transmissão de valores e de créditos e direitos de natureza financeira.

Ou seja, o critério temporal contido na hipótese tributária da CPMF realiza-se no exato momento em que ocorre o "lançamento a débito", o 'lançamento a crédito", a "liquidação de operação", o "pagamento", conforme os incisos I a VI, do art. 2ำ da Lei 9.311/1996, e a Instrução normativa no 450/2004, que disciplina a cobrança e o recolhimento da CPM F, em seu artigo 3으, conforme abaixo:

Art. 3o Constitui fato gerador da CPM F:

I - o lançamento a débito, por instituição financeira, em contas correntes de depósito, em contas correntes de empréstimo, em conta de depósito de poupança, de depósito judicial e de depósito de consignação em pagamento de que tratam os parágrafos do art. 890 da Lei $n-5.869$, de 11 de janeiro de 1973, introduzidos pelo art. 1 으 da Lei oㅡ 8.951, de 13 de dezembro de 1994, nela mantidas;

II - o lançamento a crédito, por instituição financeira, em contas correntes que apresentem saldo negativo, até o limite de valor da redução do saldo devedor;

III - a liquidação ou pagamento, por instituição financeira, de quaisquer créditos, direitos ou valores, por conta e ordem de terceiros, que não tenham sido creditados, em nome do beneficiário, nas contas referidas nos incisos anteriores;

IV - o lançamento, e qualquer outra forma de movimentação ou transmissão de valores e de créditos e direitos de natureza financeira, não relacionados nos incisos anteriores, efetuados pelos bancos comerciais, bancos múltiplos com carteira comercial e caixas econômicas;

$\mathrm{V}$ - a liquidação de operações contratadas nos mercados organizados de liquidação futura;

$\mathrm{VI}$ - qualquer outra movimentação ou transmissão de valores e de créditos e direitos de natureza financeira que, por sua finalidade, reunindo características que permitam presumir a existência de sistema organizado para efetivá-la, produza os mesmos efeitos previstos nos incisos anteriores, independentemente da pessoa que a efetue, da denominação e da forma jurídica ou dos instrumentos utilizados para realizá-la.

$\S 1$ - As contas correntes de empréstimo a que se refere 0 inciso I são constituídas pelos saldos devedores verificados nas contas correntes de depósito, resultantes de adiantamentos a depositantes, ou decorrentes de contratos de abertura de crédito sob qualquer forma.

$\S 2$ - Constituem fato gerador da CPMF, nas contas correntes de empréstimo referidas no $\S 1$, observado o exemplo constante do Anexo I:

I - o débito inicial e os demais débitos que ocorrerem posteriormente;

II - o lançamento a crédito em contas que apresentem saldo negativo, até o limite de valor da redução do saldo devedor. 
§ 3o Para efeito do disposto no inciso II do § 2ํㅡ, a contribuição incidirá sobre 0 valor correspondente à efetiva redução do empréstimo concedido nas contas correntes de depósito, apurado ao final de cada dia.

$\S 4$ Inclui-se na hipótese de ocorrência do fato gerador prevista no inciso III do caput:

I - a liquidação ou pagamento de cheques, emitidos por instituição financeira, que sejam registrados na rubrica "Ordem de Pagamento" do Plano Contábil das Instituições do Sistema Financeiro Nacional (Cosif), ressalvado o disposto no § 50;

II - o pagamento, em espécie, de salários e proventos, inclusive os de aposentadorias, pensões e outros benefícios, cujo valor não tenha sido debitado na conta corrente de depósito à vista do empregador;

III - as liquidações de ordens de pagamento, em que uma mesma pessoa seja emitente e beneficiária, cuja emissão tenha sido efetuada contra entrega de dinheiro ou cheques emitidos por terceiros à instituição financeira.

$\S 5$ o A cobrança da CPMF na liquidação ou pagamento dos cheques de que trata 0 inciso I do $\S 4$, somente será dispensada se:

I - o valor do cheque for creditado na conta de depósito do beneficiário; ou

II - o beneficiário apresentar à instituição financeira responsável pela liquidação ou pagamento declaração da instituição financeira sacada, atestando que o cheque foi emitido a débito da conta do tomador.

$\S 60$ A declaração de que trata o $\S 5$ será:

I - elaborada de acordo com o modelo constante no Anexo II e firmada pelo gerente da agência bancária emissora do cheque;

II - arquivada pela instituição financeira que liquidar ou pagar o cheque, acompanhada de cópia do mesmo, em ordem cronológica, à disposição da Secretaria da Receita Federal.

$\S 70 \mathrm{Na}$ liquidação ou pagamento a que se refere o inciso III do caput, sujeitos à contribuição, quando de valor superior a $\mathrm{R} \$ 10.000,00$ (dez mil reais), a instituição financeira deverá indicar, no correspondente registro da operação, o número de inscrição no Cadastro de Pessoas Físicas (CPF) ou no Cadastro Nacional da Pessoa Jurídica (CNPJ) do beneficiário.

$\S 8$ Caso a instituição financeira utilize recursos provenientes de créditos, direitos ou valores, inclusive decorrentes de cobrança bancária, não creditados na conta de depósito de seu titular, para efetuar qualquer pagamento por conta e ordem deste, a CPM F será calculada sobre o montante dos referidos créditos, direitos ou valores. § 9o Sujeitam-se, também, à incidência da CPMF os lançamentos efetuados em contas de caução vinculadas a licitações, quando do levantamento, pelos participantes do certame, dos valores depositados.

Assim, ocorrida a subsunção do fato à norma, forma-se um vínculo obrigacional.

Carvalho (2004, p. 281) explica que ao preceituar a conduta, fazendo irromper direitos subjetivos e deveres jurídicos correlatos, o conseqüente normativo desenha a previsão de uma relação jurídica, que se instala, automática e infalivelmente, assim que concretize 0 fato.

Formada a relação jurídica tributária, isto é, formado o laço obrigacional, 0 prescritor normativo (conseqüente) irá fornecer dois critérios de identificação dos elementos que constituem esse laço obrigacional (relação jurídica tributária), qual seja: 0 critério pessoal, que aponta sujeitos da obrigação (ativo $\rightarrow$ União, art. 149 CF/88 e passivo 
$\rightarrow$ contribuinte que efetua a movimentação ou transmissão de valores, créditos e direitos de natureza financeira) da relação; e o critério quantitativo, indicador dos fatores que, conjugados, exprimem o valor pecuniário da dívida (base de cálculo $\rightarrow$ valor da operação e alíquota $\rightarrow 0,38 \%)$.

\section{Operação simbólica de câmbio}

\section{Conceito}

As operações de câmbio simbólicas ou operações simultâneas de câmbio, consistem em transações fictícias de saída e entrada de dinheiro no país.

Referidas operações são uma espécie de mecanismo do qual dispõe o Banco Central para controlar a entrada e saída de divisas do território nacional, ou seja, uma medida de cunho eminentemente fiscalizatório.

Através da Circular no 2.997 de o Banco Central determinou que as Instituições Financeiras façam a retenção da CPMF sobre valores relativos a contratos simbólicos de câmbio. Dessa forma, os bancos operadores utilizados para contratação do câmbio realizam o desconto da quantia relativa a $0,38 \%$ (zero vírgula trinta e oito por cento $\rightarrow$ alíquota CPMF) do valor da remessa, a título da contribuição.

Havendo conversão de valores em investimentos externos no País, o Banco Central, obriga as empresas, através da Circular Bacen no 2.997/2000, a registrar contrato de câmbio, simulando uma operação.

Ainda, nos termos da Circular no 2.997/00 e Comunicado 7.845/00 do Banco Central, os contribuintes devem contratar câmbio, realizando operações simultâneas de compra e venda de moeda estrangeira, sem expedição de ordem de pagamento para 0 exterior. É o que se denominou de "remessa e ingresso do capital meramente simbólicos".

A operação de câmbio simbólica ocorre, por exemplo, nas seguintes situações:

a) quando uma empresa situada no Brasil faz um empréstimo fora do país e o pagamento do credor ocorre com a emissão de quotas ou ações do empreendimento em favor desse credor. Neste caso, o credor transforma o pagamento que receberia em investimento na empresa brasileira; 
b) na conversão de dividendos também em investimento na empresa. Percebe-se, claramente, que são dois casos de investimentos estrangeiros no país, plenamente legais.

0 problema reside no fato de que em nenhuma das mencionadas operações há saída pecuniária do país, mas é realizada apenas para cumprir exigência burocrática do Banco Central, com o fim de controlar e fiscalizar a entrada e saída de capital estrangeiro no país.

Da incidência (ou não) da CPM F nas operações simbólicas de câmbio

Com a operação simbólica de câmbio, há a entrada ou saída de dinheiro no território brasileiro. Ainda que puramente fictícia, haja vista que não existe a saída, propriamente dita, de pecúnia do país, pressupõe-se (o Fisco) que houve uma movimentação ou transmissão de valores e de créditos e direitos de natureza financeira, ou seja, realização do critério material que compõe a hipótese tributária da CPMF, gerando, a partir daí, um fato jurídico tributário, capaz de fazer nascer uma relação jurídica tributária, que irá ter como conseqüente, a obrigação de pagar esse tributo.

De acordo com a hipótese tributária da CPMF, o critério material, determinante da hipótese de sua incidência, é a movimentação ou transmissão de valores e de créditos e direitos de natureza financeira, que são efetuadas por meio de qualquer operação liquidada ou lançamento realizado por instituições financeiras, que representem circulação escritural ou física de moeda e de que resulte ou não transferência de titularidade dos mesmos valores, créditos e direitos ("Iançamento a débito", o 'lançamento a crédito", a "liquidação de operação", o "pagamento").

Logo, a crítica que se faz é que tanto a Lei 9.311/96, que institui a Contribuição Provisória sobre Movimentação Financeira - CPM F, assim como, a Instrução Normativa no 450/2004, nada dispuseram sobre as operações simbólicas de câmbio, em que há saída e

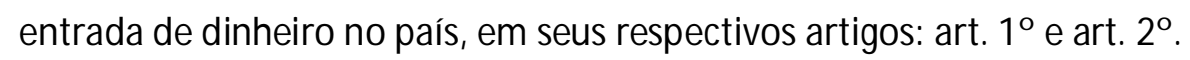

0 art. 2o Instrução normativa no 450/2004, que disciplina a cobrança e 0 recolhimento da CPMF, assim dispõe:

Art. 2o-Considera-se movimentação ou transmissão de valores e de créditos e direitos de natureza financeira qualquer operação liquidada ou lançamento realizado pelas entidades referidas no art. $3 \underline{\underline{n}}$, que representem circulação 
escritural ou física de moeda, e de que resulte ou não transferência da titularidade dos mesmos valores, créditos e direitos.

Logo em seguida, preceitua art. 3ํ da mesma IN, o seguinte:

Art. 3o Constitui fato gerador da CPMF:

I - o lançamento a débito, por instituição financeira, em contas correntes de depósito, em contas correntes de empréstimo, em conta de depósito de poupança, de depósito judicial e de depósito de consignação em pagamento de que tratam os parágrafos do art. 890 da Lei $n 05.869$, de 11 de janeiro de 1973, introduzidos pelo art. 1 을 Lei o 8.951, de 13 de dezembro de 1994, nela mantidas;

II - o lançamento a crédito, por instituição financeira, em contas correntes que apresentem saldo negativo, até o limite de valor da redução do saldo devedor;

III - a liquidação ou pagamento, por instituição financeira, de quaisquer créditos, direitos ou valores, por conta e ordem de terceiros, que não tenham sido creditados, em nome do beneficiário, nas contas referidas nos incisos anteriores;

IV - o lançamento, e qualquer outra forma de movimentação ou transmissão de valores e de créditos e direitos de natureza financeira, não relacionados nos incisos anteriores, efetuados pelos bancos comerciais, bancos múltiplos com carteira comercial e caixas econômicas;

$\mathrm{V}$ - a liquidação de operações contratadas nos mercados organizados de liquidação futura;

$\mathrm{VI}$ - qualquer outra movimentação ou transmissão de valores e de créditos e direitos de natureza financeira que, por sua finalidade, reunindo características que permitam presumir a existência de sistema organizado para efetivá-la, produza os mesmos efeitos previstos nos incisos anteriores, independentemente da pessoa que a efetue, da denominação e da forma jurídica ou dos instrumentos utilizados para realizá-la.

Analisando 0 art. 2ํ da IN 450/2004, bem como o seu art. 3o e incisos, é possível concluir que o legislador nada mencionou quanto a incidência da CPMF nas operações simbólicas de câmbio, que não importem na transferência de valores.

Dessa forma, em tais operações, não haveria que se falar em cobrança da CPMF, uma vez inexistirem quaisquer operações financeiras (movimentação ou transmissão de valores e de créditos e direitos de natureza financeira), isto é, não ocorre o fato jurídico tributário, ensejador da obrigação tributária.

Cumpre observar, que o fato de não incidir CPM F nas operações simbólicas, não se confunde com a imunidade e com a isenção.

A imunidade tributária é um fenômeno de natureza constitucional. As normas constitucionais que, direta ou indiretamente, tratam do assunto fixam, por assim dizer, a incompetência das entidades tributantes para onerar, com exações, certas pessoas, seja em 
função de sua natureza jurídica, seja porque coligadas a determinados fatos, bens ou situações. (CARRAZZA, 2005, p. 676)

Quanto às isenções, explica Carvalho (2004; p. 184), que estas estão no plano da legislação ordinária e que operam como expediente redutor do campo de abrangência dos critérios da hipótese tributária ou conseqüência da regra-matriz do tributo. A norma tributária é válida, todavia, a isenção não permite que seja efetuado o seu lançamento, com a verificação do evento tributário.

No caso em que uma empresa situada no Brasil faz um empréstimo fora do país e 0 pagamento do credor ocorre com a emissão de quotas ou ações do empreendimento em favor desse credor, transformando o pagamento que receberia em investimento, o contrato de câmbio é apenas simbólico, visto que não há movimentação financeira. Os valores não são movimentados porque já se encontram na empresa investida, só que sob a forma de empréstimo. Por conseguinte, inexistiria a incidência da CPM F sobre tais contratos.

A questão ainda não se encontra pacificada pelos Tribunais pátrios. Contudo, é possível verificar algumas decisões que resolvem pela inconstitucionalidade da cobrança da CPM F, em casos de operações simbólicas de câmbio, considerando a ausência da ocorrência o evento tributário, abstratamente descrito na hipótese tributária, conforme o seguinte julgado selecionado:

\section{EMENTA}

TRIBUTÁRIO - CPMF - CONTRATO SIM BÓUCO.

I - Na operação de câmbio simbólico não há movimentação de moeda, física ou escritural.

II - Ausência de fato gerador da CPMF no registro contábil da operação de câmbio feito para controle do BACEN, que não importa em movimentação de recursos financeiros.

III - Apelação provida e segurança concedida (12).

(TRT 2a Região, Apelação em mandado de segurança - 2002.51.01.014486 - 4, Relator: Desembargadora Federal Tânia Heine. Ementa publicada no DJU II de 14.01.2005, p. 66.)

Da decisão acima não discrepa o TRF da 3a Região(13). A seguir trechos do voto da Desembargadora Federal Alda Basto da 4a Turma:

“(...)

Referido débito foi liquidado através da conversão integral do crédito externo decorrente das importações, em investimento direto mediante o aumento de capital da empresa, ora agravante.

Assim, o pagamento da dívida deu-se com as quotas da empresa ao invés de moeda corrente, consistindo e uma operação simbólica de câmbio, ausente, portanto, a ocorrência do fato gerador da CPMF. 
Os contornos da CPMF estão definidos na Lei n. 9.311/96, compreendendo nos termos do parágrafo único, do Art. 10 da Lei n. 9.311/96 a movimenta ao ou transmissão de valores e de créditos e direitos de natureza financeira qualquer operação liquidada ou lançamento realizado pelas entidades no art. 20, que representem circulação escritural ou física de moeda, e de que resulte ou não transferência da titularidade dos mesmos valores, créditos e direitos.

A fim de assegurar a impetrante a não incidência da CPMF sobre operação consistente na conversão dos valores devidos à empresa estrangeira - débito originado por compra de maquinário - em investimento no capital da agravada, sob o fundamento de tratar-se de dação em pagamento, insuficiente para a caracterização de fato gerador,da CPM F, na forma do parágrafo único do art. 10 da Lei $n$ 9311/96.

Portanto, para que ocorra o fato gerador previsto na norma elencada é necessário que haja circulação física ou escritural de moeda. Num exame de cognição sumário, não antevejo tenha ocorrido a hipótese tributária, porquanto na transação levada a efeito não se vislumbra qualquer pagamento ou circulação financeira.

Assim, havendo nos autos elementos suficientes a amparar a pretensão do agravante, mormente por vislumbrar o perigo de dano grave e de difícil reparação DEFIRO a pleiteada suspensão dos efeitos da r. decisão agravada"

(TRT 2a Região, Apelação em mandado de segurança - 2002.51.01.014486 - 4, Relator: Desembargadora Federal Tânia Heine. Ementa publicada no DJU II de 14.01.2005, p. 66.)

Quanto à circulação física de moeda, a que se refere 0 art. 2º , da IN 450/2004, é a circulação da moeda em seu meio físico. Já, a circulação escritural consiste na criação de uma moeda pelos bancos a partir dos depósitos que recebem e que se concretiza somente na contabilidade dos próprios bancos.

Entretanto, a cobrança da CPM F sobre as operações simbólicas de câmbio é prática recorrente no país. Tanto o é, que o BACEN editou a Circular 2.997/2000, com a finalidade de fiscalizar a entrada e saída de dinheiro no país, conforme exposto em linhas acima.

Da violação aos princípios constitucionais tributários

Princípio, segundo Carrazza (2005; p. 39), é um enunciado lógico, implícito ou explícito, que, por sua grande generalidade, ocupa posição de preeminência nos vastos quadrantes do Direito e, por isso mesmo, vincula, de modo inexorável, o entendimento e a aplicação das normas jurídicas que com ele se conectam.

A cobrança da CPMF sobre as Operaç̧ões Simbólicas de Câmbio, ante a falta de previsibilidade legal tanto na Lei 9.311/1996, quanto na Instrução Normativa 450/2004, consistiria em uma verdadeira afronta ao Princípio da Legalidade ou Tipicidade Tributária, inserido no texto constitucional de 1988, no art. 5ㅇ, II e reforçado, no campo tributário, pelo 
art. 150, I, o qual veda a União, os Estados, o Distrito Federal e os Municípios, exigir ou aumentar tributo sem que a lei o estabeleça.

Ao fazer incidir CPMF sobre as operações simbólicas de câmbio, o sujeito ativo da relação jurídica tributária (União - art. 149, CF/88 - CPMF), também estaria violando o Princípio da Isonomia Tributária, com a imposição de um tratamento desigual entre o capital estrangeiro e o nacional, com previsão no art. 150, II, da CF/88. Os investidores nacionais e estrangeiros devem receber mesmo tratamento pela legislação tributária.

\section{Conclusão}

Do exposto, conclui-se que a cobrança da CPMF nas operações simbólicas de câmbio, em que há entrada e saída de dinheiro no país, revela-se inconstitucional, por violar princípios fundamentais, que circundam o sistema tributário nacional, como o da Legalidade Tributária e Isonomia, contidos na Constituição Federal de 1988. Princípios que devem ser pontualmente seguidos, tendo em vista que imprimem segurança na interpretação e aplicação das regras de cada tipo tributário, de acordo com o seu regime jurídico.

A operação em comento, consiste em um mecanismo, de que dispõe o BACEN, para fiscalizar a entrada e saída pecuniária, no território brasileiro.

Claro ficou que, nessas operações, não há movimentação ou transmissão de valores e de créditos e direitos de natureza financeira e, conseqüentemente, a hipótese tributária da CPMF não realiza o seu critério material, diante disso, não há que se falar em incidência deste tributo.

\section{Referências}

ATALIBA, Geraldo. Hipótese de incidência tributária. 6. ed. São Paulo: Malheiros, 2004.

BASTOS, Celso Ribeiro. Curso de direito tributário. 2. ed. São Paulo: Celso Bastos Editor,2002.

CARRAZZA, Roque Antonio. Curso de direito constitucional tributário. 21. ed. São Paulo: Malheiros, 2005.

CARVALHO, Paulo de Barros. Curso de direito tributário. 18. ed. São Paulo: Saraiva, 2007. ICHIHARA, Yoshiaki. Direito tributário. 14. ed. São Paulo: Atlas, 2005. 
M ACHADO, Hugo de Brito. As contribuições no sistema tributário brasileiro. São Paulo: Dialética; Fortaleza: Instituto Cearense de Estudos Tributários - ICET, 2003.

M ELO, José Eduardo Soares de. Contribuições sociais no sistema tributário. 4. ed. São Paulo: Malheiros, 2003.

PAULSEN, Leandro. Direito tributário: Constituição e Código Tributário à luz da Doutrina e da Jurisprudência. 9. ed. Porto Alegre: Livraria do Advogado, 2007. 